\title{
Importance of the inhalation device on the effect of budesonide
}

\author{
L Agertoft, S Pedersen
}

\begin{abstract}
Two hundred and forty one children with chronic perennial asthma, who had been treated with budesonide via a metered dose inhaler with a spacer device (Nebuhaler); had their normal dose of budesonide reduced by $\mathbf{5 0} \%$ to determine if they had been overtreated. Within three weeks, asthma control deteriorated in 126 patients to such an extent that budesonide had to be increased to the normal dose. After stabilising their asthma, these children were enrolled in a randomised, double blind, double dummy, parallel study, performed to compare the effect of budesonide via Nebuhaler with that of half the dose of budesonide via Turbuhaler.

The study started with a two week run-in during which patients were treated with their normal dose of budesonide via Nebuhaler. After run-in, 64 children were randomised to treatment with their normal budesonide treatment and the remaining 62 children to treatment with half their normal dose via Turbuhaler for nine weeks. Throughout the study, patients recorded asthma symptoms, peak flow measurements, and $\beta_{2}$ agonist use in a diary. Pulmonary function tests, exercise tests, and 24 hour urine sample collections were performed at hospital visits during run-in and the study period.
\end{abstract}

Apart from $\beta_{2}$ agonist use, which was significantly lower for patients on Turbuhaler treatment than on Nebuhaler treatment, there were no differences between the groups in any of the parameters studied during run-in or during the study period. Furthermore, there was no trend of deterioration in asthma control when the dose of budesonide was reduced by $50 \%$ when Turbuhaler was the inhalation device.

It is concluded that budesonide via Turbuhaler is more effective than via Nebuhaler in the treatment of asthma. Based on this finding, attempts should be made to reduce the dose of budesonide when patients are switched from Nebuhaler to Turbuhaler treatment.

(Arch Dis Child 1993; 69: 130-133)

Treatment with inhaled glucocorticosteroids via dry powder inhalers seems to be associated with a higher systemic effect than treatment via metered dose inhalers used with a spacer device. ${ }^{1-4}$ This is often assumed to be due to higher oropharyngeal deposition of drug with dry powder treatment but the bioavailability of budesonide from the oropharynx after swallowing is rather low: about $13 \% .^{5}$ It seems unlikely therefore that systemic absorption of budesonide from the oropharynx alone would cause the difference in systemic activity detected in children at daily doses as low as $400 \mu \mathrm{g}$ (S Pedersen, O R Hansen, unpublished).

In an earlier study, plasma concentrations of budesonide after inhalation via Turbuhaler (Astra) were markedly higher than the concentrations obtained after inhalation via Nebuhaler (Astra) (S Pedersen et al, unpublished), even when absorption of swallowed drug was blocked by activated charcoal. We concluded that higher drug deposition in the lungs was the cause of the increase in systemic absorption. If this is correct, treatment with budesonide via Turbuhaler should be more effective than budesonide treatment via Nebuhaler. When reviewing the literature, we found indications that this was the case, ${ }^{6-8}$ although none of the studies were designed to test this.

The aim of this study was to determine if the Turbuhaler is more effective than the Nebuhaler in controlling asthma symptoms in children with chronic asthma.

\section{Patients and methods}

Children from our outpatient clinic with asthma, well controlled for at least three months by treatment with 400 or $800 \mu \mathrm{g}$ budesonide daily via Nebuhaler, were eligible to enter a three week evaluation period. During the evaluation period, a total of 241 patients had their normal daily dose of budesonide reduced by $50 \%$. A diary was kept by each patient and morning and evening peak expiratory flow rate (PEFR), night and day asthma symptoms (rated between 0-3), and the use of rescue terbutaline sulphate (Bricanyl Turbuhaler) were recorded. If the clinical condition deteriorated, the dose of budesonide was doubled (that is, increased to the dose at which the child was normally well controlled $=$ normal dose).

Asthma was considered to have deteriorated if one of the following occurred on three or more consecutive days: (i) a fall in morning PEFR $>25 \%$; (ii) diurnal variation in PEFR $>25 \%$; (iii) use of $>4$ inhalations of terbutaline sulphate per day; (iv) more than one step worsening in symptoms scores (that is, from $0-2$ or from $1-3$ etc).

The clinical condition of 126 of the 241 children deteriorated during the three week evaluation period. After their asthma had stabilised on their normal dose of budesonide, these children were included in a randomised, double blind, double dummy, parallel study involving a two week run-in period and a nine week treatment period. The remaining 115 children were not included.

During the run-in period, all children were treated with their normal dose of budesonide via 
Nebuhaler. At the start of the treatment period, 62 children were randomly allocated to treatment with Turbuhaler at half their normal dose of budesonide and 64 children to treatment with Nebuhaler at their normal dose of budesonide. Budesonide was always taken in the morning and in the evening. The patients were advised to take their medication just before brushing their teeth in order to ensure effective mouth rinsing after each treatment. All children used inhaled terbutaline sulphate when needed. No other drugs for asthma were allowed. If deterioration of the asthma condition occurred, as defined in the evaluation period, it was considered a 'treatment failure' and the patient was withdrawn from the study.

Throughout the study, diary recordings continued as during the evaluation period. Patients visited the outpatient clinic at the beginning and end of the run-in period and half way through and at the end of the treatment period. At each visit, pulmonary function was measured on a Vitalograph compact. Forced expiratory vital capacity (FVC)(1), forced expiratory volume in one second $\left(\mathrm{FEV}_{1}\right)(\mathrm{l}), \mathrm{PEFR}(1 / \mathrm{min})$, and forced midexpiratory flow $\left(\mathrm{FEF}_{25-75 \%}\right)(\mathrm{l} / \mathrm{sec})$ were used as variables in the comparison analysis. At the end of the run-in and the study period, the children performed a standardised exercise test.

Table 1 Patient characteristics during the run-in period. Values are given as mean $(S D)$, except for age where mean and range are given

\begin{tabular}{|c|c|c|}
\hline Variable & Turbuhaler & Nebuhaler \\
\hline $\begin{array}{l}\text { No of patients } \\
\text { No of patients on } 800 \mu \mathrm{g} \\
\text { No of patients on } 400 \mu \mathrm{g} \\
\text { Age (years) } \\
\text { Boy/girl } \\
\text { Height }(\mathrm{cm}) \\
\text { Weight }(\mathrm{kg}) \\
\text { FVC (1) } \\
\text { FEV }_{1}(1) \\
\text { FEV }_{25-75 \%}(1 / \mathrm{sec}) \\
\text { Urine cortisol (nmol/24 hours) }\end{array}$ & $\begin{array}{l}62 \\
36 \\
26 \\
9 \cdot 5(5-15) \\
44 / 18 \\
139(18) \\
34(13) \\
2 \cdot 7(1 \cdot 1) \\
2 \cdot 0(0 \cdot 8) \\
1 \cdot 8(0 \cdot 8) \\
32 \cdot 7(19)\end{array}$ & $\begin{array}{l}64 \\
38 \\
26 \\
9 \cdot 0(4-15) \\
43 / 21 \\
137(18) \\
33(11) \\
2 \cdot 5(1 \cdot 0) \\
1 \cdot 9(0 \cdot 7) \\
1 \cdot 8(0 \cdot 8) \\
31 \cdot 5(17)\end{array}$ \\
\hline
\end{tabular}

Table 2 Mean values of pulmonary function and of $\%$ fall in pulmonary function during the treadmill test measured at clinic visits

\begin{tabular}{|c|c|c|c|c|c|c|c|}
\hline & \multicolumn{3}{|c|}{ Turbuhaler } & \multicolumn{3}{|c|}{ Nebuhaler } & \multirow[b]{2}{*}{$\begin{array}{l}\text { 95\% Confidence } \\
\text { intervals }\end{array}$} \\
\hline & Run-in & $\stackrel{9}{\text { Weeks }}$ & $\begin{array}{l}\text { Change } \\
\text { from } \\
\text { run-in }\end{array}$ & Run-in & $\stackrel{9}{\text { Weeks }}$ & $\begin{array}{l}\text { Change } \\
\text { from } \\
\text { run-in }\end{array}$ & \\
\hline $\begin{array}{l}\text { FEV }_{1}(\mathrm{l}) \\
\text { FVC }(\mathrm{l}) \\
\text { FEF }_{25}-75 \%(1 / \mathrm{sec}) \\
\% \text { Fall in FEV }_{1} \\
\% \text { Fall in FVC } \\
\% \text { Fall in FEF } \\
\text { \% Fall in PERF }\end{array}$ & $\begin{array}{r}2 \cdot 0 \\
2 \cdot 7 \\
1 \cdot 8 \\
15 \cdot 5 \\
11 \cdot 0 \\
30 \cdot 7 \\
17 \cdot 1\end{array}$ & $\begin{array}{r}2 \cdot 1 \\
2 \cdot 8 \\
1 \cdot 9 \\
11 \cdot 1 \\
6 \cdot 4 \\
22 \cdot 7 \\
11 \cdot 2\end{array}$ & $\begin{array}{r}0 \cdot 11 \\
0 \cdot 12 \\
0 \cdot 12 \\
-3 \cdot 52 \\
-5 \cdot 02 \\
-5 \cdot 42 \\
-5 \cdot 46\end{array}$ & $\begin{array}{r}1 \cdot 9 \\
2 \cdot 5 \\
1 \cdot 8 \\
12 \cdot 4 \\
7 \cdot 6 \\
24 \cdot 8 \\
15 \cdot 1\end{array}$ & $\begin{array}{r}2 \cdot 0 \\
2 \cdot 6 \\
2 \cdot 0 \\
12 \cdot 3 \\
6 \cdot 9 \\
27 \cdot 6 \\
13 \cdot 0\end{array}$ & $\begin{array}{r}0.12 \\
0.13 \\
0 \cdot 15 \\
-0.50 \\
-1.06 \\
2.49 \\
-2.46\end{array}$ & $\begin{array}{l}(-0.09 \text { to } 0.11) \\
(-0.10 \text { to } 0.12) \\
(-0.17 \text { to } 0.23) \\
(-3.00 \text { to } 9.04) \\
(-1.24 \text { to } 9.16) \\
(-3.77 \text { to } 19.59) \\
(-4.11 \text { to } 10.11)\end{array}$ \\
\hline
\end{tabular}

^Difference between Nebuhaler and Turbuhaler.

Table 3 Mean values for efficacy variables recorded at home in patient diaries

\begin{tabular}{|c|c|c|c|c|c|c|c|}
\hline & \multicolumn{3}{|c|}{ Turbuhaler } & \multicolumn{3}{|c|}{ Nebuhaler } & \multirow[b]{2}{*}{$\begin{array}{l}95 \% \text { Confidence } \\
\text { intervals }\end{array}$} \\
\hline & Run-in & $\stackrel{9}{\text { Weeks }}$ & $\begin{array}{l}\text { Change } \\
\text { from } \\
\text { run-in }\end{array}$ & Run-in & $\stackrel{9}{\text { Weeks }}$ & $\begin{array}{l}\text { Change } \\
\text { from } \\
\text { run-in }\end{array}$ & \\
\hline \multirow[t]{2}{*}{$\begin{array}{l}\text { Morning PEFR }(1 / \mathrm{min}) \\
\text { Evening PEFR }(1 / \mathrm{min}) \\
\text { Night symptoms }(0-3) \\
\text { Day symptoms }(0-3) \\
\text { Terbutaline sulphate } \\
\text { use (doses/week) }\end{array}$} & $\begin{array}{l}287 \\
297 \\
0 \cdot 33 \\
0 \cdot 60\end{array}$ & $\begin{array}{l}301 \\
308 \\
0 \cdot 13 \\
0 \cdot 33\end{array}$ & $\begin{array}{c}14.9 \\
11 \cdot 4 \\
-0.21 \\
-0.26\end{array}$ & $\begin{array}{l}278 \\
287 \\
0 \cdot 32 \\
0 \cdot 76\end{array}$ & $\begin{array}{l}291 \\
299 \\
0 \cdot 18 \\
0 \cdot 46\end{array}$ & $\begin{array}{l}11 \cdot 5 \\
10.4 \\
-0.15 \\
-0.30\end{array}$ & $\begin{array}{l}(-14 \cdot 00 \text { to } 7 \cdot 18) \\
(-10 \cdot 24 \text { to } 8 \cdot 18) \\
(-0 \cdot 12 \text { to } 0 \cdot 24) \\
(-0 \cdot 27 \text { to } 0 \cdot 19)\end{array}$ \\
\hline & $3 \cdot 83$ & $3 \cdot 83$ & 0.00 & 3.56 & $4 \cdot 67$ & $1 \cdot 15$ & $(0.34$ to 1.96$)$ \\
\hline
\end{tabular}

^Difference between Nebuhaler and Turbuhaler.
The exercise test involved six minutes on a treadmill with the workload adjusted to cause a pulse rate of 170 or more during the last three minutes of exercise. Children wore a nose clip during the test and temperature and air humidity were recorded. $\mathrm{FEV}_{1}, \mathrm{FVC}, \mathrm{FEF}_{25-75 \%}$, and PEFR were measured before and $1,3,5,8,10$, 15 , and 20 minutes after the test or until a maximum fall had occurred. Two reproducible lung function curves were obtained and the one with the highest $\mathrm{FEV}_{1}$ was used for calculations. The maximum per cent fall in the various pulmonary function parameters was used as variables in the comparison analysis.

Compliance with the dosing regimens was estimated by weighing the metered dose inhaler canisters before and after the study and by calculating the number of doses remaining as indicated by the 'doses remaining indicator' on the Turbuhaler.

Twenty four hour urine cortisol excretion was determined for two consecutive days at the end of run-in and at the end of the treatment period. Day and night urine samples were collected in separate bottles.

The study was approved by the local ethics committee and informed assent/consent was obtained from all children/parents.

\section{STATISTICS}

Sample size determination was based on diary PEFR in previous studies. We estimated the SD of a change in PEFR to be about $15 \%$ of the predicted normal PEFR. With 60 patients in each group, we had an $80 \%$ chance of detecting a significant difference with a $t$ test at the $5 \%$ significance level if the true difference was $8 \%$ of the predicted normal PEFR.

All variables were analysed using a two way analysis of variance (ANOVA) model with fixed factors for treatment, dose, and interaction. For some variables, an additional ANOVA analysis using rank transformed responses has been performed. Measured values and differences between mean values at run-in and at the end of the treatment period were used as the responses for comparison; $p<0.05$ was considered statistically significant.

\section{Results}

There were no statistically significant differences between the randomised groups in terms of demographic data, pulmonary function measured at the clinic, or urine cortisol excretion during the run-in period (table 1). No significant change in any of the recorded variables occurred for either group during run-in, indicating that the patients' asthma condition had stabilised before entering the run-in.

The results of the separate efficacy analyses for high and low dose subgroups are not presented because dose at entry did not influence the results or conclusions. Therefore, data from all 126 patients were used in the comparisons between the two groups. Results of the urine cortisol excretion analysis are, however, presented for the high and low dose subgroups.

One patient from the Nebuhaler group and 
one from the Turbuhaler group did not complete the study due to deterioration of asthma.

\section{OUTCOME VARIABLES}

Mean values for all recorded efficacy variables, the changes from run-in to the end of treatment, and the corresponding confidence intervals for the differences are presented in table 2 for clinic visit data and in table 3 for diary data.

The only statistically significant difference between the treatment groups was in the use of rescue terbutaline sulphate. Use was higher in the Nebuhaler group. No other differences were found in any of the diary or clinic efficacy variables between treatment groups. Diary variables for both groups tended to improve during the treatment period but the improvements were not statistically significant.

The narrow confidence intervals indicate that the interpatient variance was of little significance and that the risk of not detecting differences between the treatments if there had been any was very low.

\section{URINE CORTISOL EXCRETION}

Twenty four hour urine cortisol excretion during run-in and the treatment period is depicted in the figure. The changes from run-in to the end of treatment were similar for both treatment and dose groups: $0.49 \mathrm{nmol}$ for the Nebuhaler and $1.83 \mathrm{nmol}$ for the Turbuhaler $(\mathrm{p}=0 \cdot 19)$. Separate day and night cortisol excretion analyses did not demonstrate any differences between the treatments.

\section{COMPLIANCE}

Overall compliance was good and did not differ between treatment groups.

\section{Discussion}

It is often assumed that the same dose of drug, although delivered via different inhalation devices, has the same clinical effect. In accordance with this earlier comparison, studies have been performed to demonstrate equivalence between the Turbuhaler and other devices. These studies have all been short term crossover studies involving a limited number of patients whose asthma was well controlled on budesonide via Nebuhaler at entry. Under such conditions, detecting a significant improvement in asthma would have been difficult. Nevertheless, there

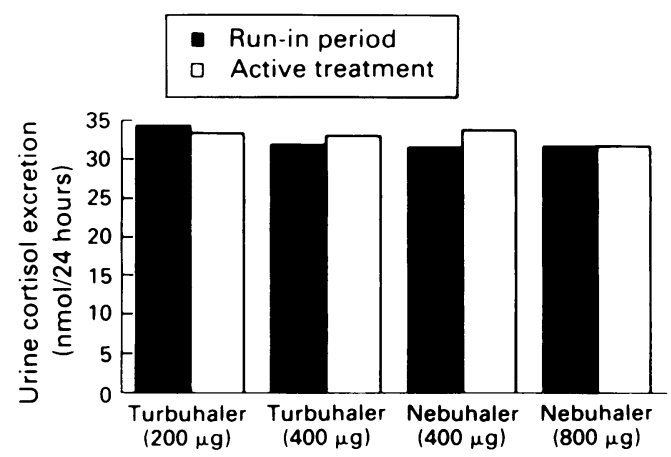

was a trend in all of the studies (statistically significant for some variables) indicating better clinical effect by Turbuhaler treatment. ${ }^{6-8}$

In the present study, we chose to reduce the budesonside dose via Turbuhaler by $50 \%$ based on pharmacokinetic studies in children (S Pedersen et al, unpublished) and adults (L Thorsson, S Edsbäcker, British Thoracic Society meeting, December 1992) that suggest that intrabronchial deposition of budesonide via Turbuhaler treatment is twice as high as that via a metered dose inhaler or Nebuhaler. In addition, we had performed preliminary filter studies to measure the amount of budesonide that is delivered to a child using an optimal inhalation technique with the Turbuhaler or Nebuhaler. These results, together with the results of in vitro particle distribution studies, also suggested a 2:1 potency between Turbuhaler and Nebuhaler.

In studies comparing inhalation devices, it is important that patients are not overtreated at study entry and, therefore, on the upper flat part of the dose-response curve. To avoid this, only patients who had recently demonstrated a need for their prescribed dose of budesonide were included. The tendency for asthma symptoms and pulmonary function to improve throughout the study period suggested that the children were not overtreated at entry. Furthermore, the rather frequent use of rescue terbutaline sulphate during the run-in and the treatment period is another indication that we were successful in selecting an appropriate patient population.

The steady improvement in pulmonary function throughout the study could have been due to an improvement in compliance, which is common during clinical studies, or to the fact that the study was conducted between January and July; spring and early summer are normally 'good periods' for children with asthma in Denmark.

Before the study, we believed that all of the 241 children who participated in the evaluation period would be sensitive to a reduction in their dose of inhaled budesonide. The evaluation period, however, was only three weeks long and most of the 115 children whose asthma did not deteriorate experienced a deterioration later when they continued on the reduced budesonide dose via Nebuhaler. This observation emphasises the importance of performing studies with inhaled corticosteroids for a sufficient duration. The treatment period in the present study was about three times longer than the period shown to cause a previous deterioration in the asthma condition for all participants. Therefore, we believe that the observation period was adequate to detect a difference in effect between the two inhalers. Although the recruitment of children for the study took place during winter, viral infections were rare and never the cause of deteriorations in asthma control during the evaluation period in the children who were included in the study. Therefore seasonal differences in viral infections could not explain the difference in clinical deterioration between the evaluation (recruitment) period and the Turbuhaler treatment period when the budesonide dose was halved.

When a statistical analysis does not demonstrate a difference between two treatments, there 
is still a possibility of making a statistical type II error. With the confidence intervals achieved in the present study however, we are sure that differences that might have existed were of no clinical significance. In fact, for most variables, treatment with half the dose of budesonide via Turbuhaler tended to have a better effect than budesonide via Nebuhaler. The difference, in favour of the Turbuhaler, was statistically significant for the use of rescue terbutaline sulphate. We are, therefore, confident in our conclusion that there is a $2: 1$ potency between budesonide via Turbuhaler and via Nebuhaler.

In an earlier dose-response study we found that the exercise test was more sensitive than diary recordings and pulmonary function in detecting differences between various doses of budesonide. ${ }^{9} \mathrm{~A}$ difference in daily dose of $100 \mu \mathrm{g}$ produced significant differences in fall in pulmonary functions after exercise. ${ }^{9}$ Therefore, an exercise test was included in the assessment in the present study. However, this test could not detect any difference between the two inhalers either.

Clinical studies have been performed that did not demonstrate a difference in effect between terbutaline sulphate via Turbuhaler or via Nebuhaler. ${ }^{10-12}$ We suspect, however, that the doses of terbutaline used in these studies may have been too high to demonstrate a difference in clinical effect. Nevertheless, in pharmocokinetic studies of terbutaline sulphate, administration of the same dose via Turbuhaler has resulted in higher plasma concentrations of drug than via Nebuhaler. ${ }^{11}$ As orally deposited terbutaline has a low bioavailability, we believe the higher plasma concentrations are also in the case of terbutaline due to a higher intrapulmonary deposition with Turbuhaler. Further studies are needed to confirm this.

It has been demonstrated in earlier studies that budesonide via Nebuhaler in doses up to $800 \mu \mathrm{g}$ a day does not suppress urine cortisol excretion in children with asthma. ${ }^{13}$ Treatment with 400 $\mu \mathrm{g}$ budesonide a day via Turbuhaler is, however, associated with a statistically significant suppression of cortisol excretion in the urine (S Pedersen, O R Hansen, unpublished). In the present study, no dose related effect on urine cortisol excretion was detected by either inhaler. This discrepancy may be due to the fact that patients in the earlier Turbuhaler study were not requested to rinse their mouths out after taking their dose of budesonide. Rinsing out one's mouth after inhaling has been shown to reduce the systemic effect of the Turbuhaler. ${ }^{4}$ It then appears that budesonide at half the dose via Turbuhaler, when good mouth rinsing techniques are used, has approximately the same therapeutic effect/systemic effect ratio as budesonide via Nebuhaler, the current device of choice for treatment with high doses of budesonide.

Despite attempts to make the study as sensitive as possible to reductions in the effects of asthma treatment and to control some important confounding factors, the study clearly indicated that budesonide via Turbuhaler is clinically more effective than via Nebuhaler. We suggest, therefore, that an attempt should be made to reduce the budesonide dose of any patient being switched from Nebuhaler to Turbuhaler, otherwise the asthma will be overtreated and the patient at increased risk of unwanted systemic side effects. Exactly how much the dose can be reduced must be assessed on an individual basis but our findings suggest that a $50 \%$ reduction is possible for most patients.

\section{CONCLUSION}

No difference in effect or safety was detected between budesonide treatment via Nebuhaler and treatment at half the dose via Turbuhaler. In patients with asthma well controlled by budesonide via Nebuhaler, dose reduction should be attempted if they are switched from Nebuhaler to Turbuhaler treatment, in order to avoid unnecessary overtreatment and systemic side effects.

1 Prahl $P$, Jensen $T$. Decreased adreno-cortical suppression utilizing the Nebuhaler for inhalation of steroid aerosols. Clinical Allergy 1987; 17: 393-8.

2 Farrer M, Francis AJ, Pearce SJ. Morning serum cortisol concentrations after $2 \mathrm{mg}$ inhaled beclomethasone dipropionate in normal subjects: effect of a $750 \mathrm{ml}$ spacing device. Thorax 1990; 45: 740-2

3 Brown PH, Blundell G, Greening AP, Crompton GK. Do large volume spacer devices reduce the systemic effects of high dose inhaled corticosteroids? Thorax 1990; 45: 736-9.

4 Selroos $\mathrm{O}$, Halme $\boldsymbol{M}$. Effect of a volumatic spacer and mouth rinsing on systemic absorption of inhaled corticosteroids from a metered dose inhaler and a dry powder inhaler. Thorax 1991; 46: 891-4.

5 Ryrfeld $\AA$, Edsbäcker S, Tönneson M, et al. Pharmacokinetics and metabolism of budesonide, a selective glucocorticoid. Eur $\mathcal{F}$ Respir Dis 1982; 63(suppl 122): 86-95.

6 Engel T, Heinig JH, Malling H-J, Scharling B, Nikander K Madsen F. Clinical comparison of inhaled budesonide delivered either via pressurized metered dose inhaler or Turbuhaler. Allergy 1989; 44: 220-5.

7 Hetta L, Larsson LG, Nikander K. A comparative clinical study of inhaled budesonide delivered either via a pressurized metered dose inhaler or via Turbuhaler. Eur Respir $\mathcal{f}$ $1989 ; 2: 832 \mathrm{~s}$.

8 Hultquist C, Ahlström H, Kjellman N-IM, Malmqvist L- $\AA$, Svenonius E, Melin S. A double-blind comparison between a new multidose powder inhaler (Turbuhaler) and metered dose inhaler in children with asthma. Allergy 1989; 44: 46770.

9 Pedersen S, Hansen OR. Budesonide treatment of asthma in children: a dose-response study. Eur Respir 71993 (in press).

10 Johnson CR, Weeke ER. Turbuhaler: a new device for dry powder inhalation. Allergy 1988; 43: 392-5.

11 Fuglsang G, Pedersen S. Comparison of a new multidose powder inhaler with a pressurized aerosol in children with asthma. Pediatr Pulmonol 1989; 7: 112-5.

12 Persson G, Gruvstad E, Ståh E. A new multiple dose powder inhaler (Turbuhaler) compared with a pressurized inhaler in a study of terbutaline in asthmatics. Eur Respir $\mathcal{F} 1988 ; 1$ $681-4$

13 Bisgaard H, Pedersen S, Damkjær Nielsen M, Østerballe O. Adrenal function in asthmatic children treated with inhaled budesonide. Acta Paediatr Scand 1991; 80: 213-7. 